\title{
Preparation and evaluation of novel bamboo-polymer composites
}

\author{
L. Bhowmik and J. K. Ray* \\ Department of Chemistry, Indian Institute of Technology, \\ Kharagpur 721302, India
}

\begin{abstract}
Monomer impregnated bamboo fibres were polymerized by radically initiated polymerization technique to prepare novel composite materials. These composites exhibit close to a linear elastic behaviour. Scanning electron microscopic studies of these composites reveal a uniform incorporation of polymer into bamboo fibre matrix. These composites are also thermally stable. In view of the very low cost and ease of processing and manufacturing associated with bamboo-polymer composites, it is revealed that they offer an attractive possibility for exploitation as commercially viable biocompatible material for various structural applications.
\end{abstract}

Keywords. Composites, polymer impregnated, radical initiator, thermal stability.

* Corresponding author 


\section{Introduction}

Fibre reinforced composite materials using synthetic resins have achieved significant development in the last few decades because of their desirable properties such as light weight, high strength to weight ratio and comparatively easy processability. Most commercially important composites are based on glass fibre as the reinforcing material. Other fibres that have been successfully utilized for composite preparation include carbon, boron, asbestos fibres etc ${ }^{1-5}$. Sophisticated preparation techniques and high production cost limited the use of synthetic fibres like aramid, glass, carbon, silica, alumina, silicon carbide etc. Of late, cellulose has been used as a substitute for synthetic fibre especially for polymer matrix composites. Among known natural fibres, jute, coir, sisal, ramie, banana fibre have relatively low or poor mechanical strength ${ }^{6-9}$. Bamboo is one of the fastest growing plants and is abundantly available in most countries. However, work reported to date on bamboo fibre reinforced composite is very limited and a thorough study is warranted in view of its unique structure, vis-à-vis many attractive bulk properties of its composites ${ }^{10-13}$. There has also been a rising trend in the use of polymers and polymer composites and macromolecules mostly from bio-available sources for a host of applications encompassing medical diagnosis, therapy, agriculture and sustainable building materials $^{2,4,8,14-40}$.

Bamboo, a natural ligno-cellulosic composite, is attracting more attention of scientists and engineers owing to its unique biological structure. Plants on the earth develop their structure to adapt to various environments over a long period of time. Bamboo may be a typical example of plant with highly developed architecture. The geometry of bamboo longitudinal profile has a microscopically functional graded structure that helps it to withstand extreme natural environment ${ }^{41,42}$ and it is a unique example of unidirectional fiber reinforced composite. It has been observed that the fibre distribution in the cross section at any particular height is dense in the outer region and spares in the inner surface. As a result, the outer portion exhibits a higher strength than the inner core. The fibre strength is $600 \mathrm{MPa}$, which is 12 times higher than the matrix strength and the corresponding Young's modulus of the fiber is also much larger than that of the matrix. In addition to these investigations, the use of bamboo as a structural material as much as a reinforcement of composite material is also wide and competitive. Several attempts have been made in the past to study the mechanical properties such as modulus and strength of bamboo and bamboo composite ${ }^{1,10,41,42}$. These studies include testing of whole bamboo as well 
sections, strips and fibres of bamboo. Amada et al. examined the structure variation in bamboo with cross section and height ${ }^{41}$. The fraction of cellulosic fibre varied from $15-20 \%$ to $60-65 \%$. Tensile strength and modulus varied from 100 to $600 \mathrm{MPa}$ and 3 to $15 \mathrm{GPa}$, respectively. Jain et al. reported the anatomical properties of bamboo and bamboo fibre reinforced plastic with different orientations. They evaluated tensile, flexural and impact strength of bamboo and

bamboo fiber reinforced plastic composite with different orientations ${ }^{43}$. Shin and coworkers fabricated and tested bamboo strips and epoxy resin composite ${ }^{44}$. They observed that the epoxy resin composite is superior in strength to that of glass-fibre reinforced epoxy resin and have greater durability.

In our work we have tried to remove either full or partial matrix part of bamboo keeping the overall structure of bamboo undisturbed. Our main aim was to develop a durable and higher strength bamboo polymer composite having structurally stronger polymer components.

\section{Experimental}

\subsection{Materials}

Bamboo (B) specimens used in the present investigation viz. Valqua were collected from southern part of West Bengal, India. The bamboo specimen was air dried for 30 days in the open atmosphere.

Methyl methacrylate (MMA), methyl acrylate (MA) and styrene (S) were purchased from Qualigens, India. The monomers were purified with 5\% sodium hydroxide solution followed by washing with distilled water. Finally, the washed monomer was dried over fused calcium chloride and distilled under vacuum. Phenol (AR) (E. Merck, India) was used after distillation. Formaldehyde (Qualigens, India) and $\mathrm{NaOH}$ (G.R) (E. Merck, India) were used as received.

\subsection{Preparation and conditioning of bamboo specimen}

For polymer impregnation in bamboo strips, dumbbell shaped specimens were used keeping in view the measurement of mechanical properties of the bamboo-polymer composites. Tensile specimens were treated with $15 \% \mathrm{NaOH}$ solution to partially remove the matrix as reported in literature $^{45}$. This parameter was chosen to optimize matrix removal keeping the overall structure 
of bamboo undisturbed. Alkali treatment changed the colour of the bamboo fibre from brown to pale yellow. The samples were then thoroughly washed with distilled water to ensure complete removal of alkali and subsequently dried in an oven at $60{ }^{\circ} \mathrm{C}$ for overnight.

Alkali treated bamboo specimens were soaked with different monomers, viz. MMA, MA, $\mathrm{S}$ at $25^{\circ} \mathrm{C}$ for $2 \mathrm{~h}$. In situ polymerization of these monomers within the bamboo specimen was carried out in a specially designed reaction vessel fitted with inlet and outlet system for deaeration. For soaking with different monomers, the alkali treated specimens were separately immersed within the vessel in $40 \%$ benzene solution of MA, MMA and S containing $0.1 \%$ benzoyl peroxide as initiator in each case. The contents in the reaction vessel were deaeriated by passing dry $\mathrm{N}_{2}$ for $1 \mathrm{~h}$. The polymerization of the respective monomer soaked within the bamboo matrix was carried out by placing the vessel in a constant temperature bath at $70{ }^{\circ} \mathrm{C}$ for about $4 \mathrm{~h}$. After polymerization, the specimens were removed from the vessel. The outer surface of the composite washed with solvent to remove the adhered polymer and dried in a vacuum oven at 60 ${ }^{\circ} \mathrm{C}$ to remove the unconverted monomer and benzene.

For in situ formation of phenol-formaldehyde resin within the bamboo specimen, the $15 \%$ alkali treated bamboo specimens were heated in aqueous solution of phenol and formaldehyde $(1: 1.2 \mathrm{~mol})$ in presence of sodium hydroxide catalyst at $95-100{ }^{\circ} \mathrm{C}$ for $2 \mathrm{~h}$. The phenolic resin (resol) soaked bamboo specimens were cured at $150{ }^{\circ} \mathrm{C}$ for $10 \mathrm{~min}$ in an oven. The percentage of different polymer loading within the bamboo specimen, measured gravimetrically, was calculated using the following equation:

$$
\% \text { Polymer loading }=\frac{X-Y}{Y} \times 100
$$

Where, $\mathrm{X}$ is the weight of the bamboo specimen plus polymer formed and $\mathrm{Y}$ is the weight of the original bamboo specimen.

\subsection{Characterization and Techniques}

In order to measure the water absorption behaviour, the raw bamboo and bamboo-polymeric composites were cut into small pieces. These cut specimens were finely filed to remove any flaws. Before testing, the specimens were dried in an oven at $50^{\circ} \mathrm{C}$ for $2 \mathrm{~h}$ and kept over fused 
$\mathrm{CaCl}_{2}$ for $24 \mathrm{~h}$ followed by weighing to record the initial weight $\left(\mathrm{W}_{1}\right)$. Then these samples were immersed in distilled water for $72 \mathrm{~h}$ at room temperature, taken out and wiped well with filter paper. The swelled weight $\left(\mathrm{W}_{2}\right)$ was measured again carefully and water absorption was calculated using the following equation:

$$
\% \text { Water absorption }=\frac{W_{2}-W_{1}}{W_{1}} \times 100
$$

Finely ground bamboo-polymer composite powder was used for FTIR analysis in $\mathrm{KBr}$ pellet by Thermo Nicolet FTIR Spectrophotometer (Model Nexus 870).

Tensile properties of virgin untreated bamboo specimens, alkali treated bamboo specimens, and bamboo polymer composite specimen were measured by using a universal testing machine (according to ASTM D-638-82) The dumbbell shaped specimens had a gauze length of $5 \mathrm{~mm}$. A crosshead separation speed of $10 \mathrm{~mm} / \mathrm{min}$ was used. Five specimens of each sample were tested. Specimens under tensile test were loaded until fracture developed.

Thermal analysis of bamboo-polymer composites was performed on a Shimadzu DT-40 unit, under $\mathrm{N}_{2}$ atmosphere at a heating rate of $10{ }^{\circ} \mathrm{C} \mathrm{min}^{-1}$. The analyses were performed from room temperature to $900{ }^{\circ} \mathrm{C}$.

Fracture surface morphology of the bamboo-polymer composite specimen was studied by a scanning electron microscope (Cam Scan 2DV unit) with various magnifications.

\section{Results and discussion}

The compositions of the bamboo-polymer composites as well as the composite specimen designations are shown in Table 1. In this investigation only the polymer impregnation within the bamboo matrix was desired, ignoring whether it occurred by grafting or homopolymerization. It is seen from Table 1 that maximum polymer loading within the bamboo matrix occurred in the cases of PMMA and phenolic resin in the same period of polymer formation. It was also interestingly observed that polymerization of styrene and acrylic monomers in bulk provided higher polymer loading than that in benzene solution. 
During solution polymerization concentration of polymer was low, for this reason low incorporation of polymer took place. The main reason behind this observation was their different rates of conversion to polymers.

Table 1. Composition of bamboo-polymer composites.

\begin{tabular}{|l|l|l|l|l|}
\hline $\begin{array}{l}\text { Designation of } \\
\text { composite }\end{array}$ & Polymer matrix & $\begin{array}{l}\text { Polymerization } \\
\text { medium }\end{array}$ & $\begin{array}{l}\% \\
\text { Polymer } \\
\text { loading }\end{array}$ & $\begin{array}{l}\text { Density } \\
\left(\mathrm{g} / \mathrm{cm}^{3}\right)\end{array}$ \\
\hline B-PMMA (bul.) & Poly(methyl methacrylate) & -- & 24.4 & 1.21 \\
B-PMA (bul.) & Poly(methyl acrylate) & -- & 14.4 & 1.16 \\
B-PS (bul.) & Poly (styrene) & -- & 12.6 & 1.12 \\
B-PMMA (sol.) & Poly(methyl methacrylate) & Benzene & 8.5 & 1.11 \\
B-PMA (sol.) & Poly(methyl acrylate) & Benzene & 5.1 & 1.09 \\
B-PS (sol.) & Poly(styrene) & Benzene & 7.7 & 1.10 \\
B-PF & Phenol-formaldehyde & Water & 24.4 & 1.19 \\
Virgin bamboo & -- & -- & -- & 0.70 \\
\hline
\end{tabular}

\subsection{IR analysis}

In order to assess physical entrapment and chemical attachment of the polymer molecules, if any, to the bamboo matrix, FTIR analysis of the composite specimens was done. FTIR spectrum of pure bamboo is shown in Figure. 1. Assignments of important IR bands are given in Table 2. The bands match well with the literature value.

Table 2. Characteristic infrared absorption bands of the bamboo and bamboo-polymer composites.

\begin{tabular}{|c|c|c|c|c|c|}
\hline \multirow[t]{2}{*}{ Characteristic band } & \multicolumn{5}{|c|}{ Wave Number $\left(\mathrm{cm}^{-1}\right)$} \\
\hline & Virgin B & \begin{tabular}{|l|} 
B- \\
PMMA
\end{tabular} & B-PMA & B-PS & $\mathrm{B}-\mathrm{PF}$ \\
\hline $\mathrm{O}-\mathrm{H}$ str band (bonded) & 3444 & 3440 & 3446.51 & 3420.43 & 3403.14 \\
\hline $\mathrm{C}-\mathrm{H}$ str. band of $\mathrm{CH}_{3}$ or $\mathrm{CH}_{2}$ & 2919 & 2923 & 2861.03 & 2933.27 & 2901.07 \\
\hline $\mathrm{O}-\mathrm{CH}_{3}$ str. & -- & 2851 & -- & -- & -- \\
\hline C-H str. of aldehyde & -- & 2645 & -- & -- & -- \\
\hline $\mathrm{C}=\mathrm{O}(\mathrm{H}-$ bonded $)$ & -- & 1634.60 & 1615.49 & 1626.31 & 1619.21 \\
\hline $\begin{array}{l}\text { Aromatic moiety of lignin } \\
\text { Skeletal vibration of cellulose } \\
\text { and hemicellulose }\end{array}$ & $1432-1227$ & $1449-1262$ & $1460-1284$ & $1435-1216$ & $1414-1208$ \\
\hline
\end{tabular}


In every spectrum there was an intense broad band near about $3440 \mathrm{~cm}^{-1}$ for $\mathrm{O}-\mathrm{H}$ stretching and hydrogen bonded $\mathrm{O}-\mathrm{H}$ stretching of bamboo matrix, bamboo-polymer composite and also some moisture present in bamboo. Sharp peaks in the region $2919 \mathrm{~cm}^{-1}-2923 \mathrm{~cm}^{-1}$ appeared due to C$\mathrm{H}$ stretching of methyl and methylene groups present in both bamboo and bamboo- polymer composites. Few sharp and weak peaks in the region of $1269-1426 \mathrm{~cm}^{-1}$ in all bamboo and bamboo-polymer composites are designated to the skeletal vibration of cellulose, hemicellulose and lignin aromatic moiety. However, the appearance of peaks at $2851 \mathrm{~cm}^{-1}$ and $1384 \mathrm{~cm}^{-1}$ in the spectra of B-PMMA composite indicated the presence of $\mathrm{O}-\mathrm{CH}_{3}$ and $\mathrm{C}-\mathrm{H}$ symmetric deformation of $\mathrm{CH}_{3}$ group of PMMA. Moreover, the presence of a sharp peak at $2654 \mathrm{~cm}^{-1}$ was characteristic of the $\mathrm{C}-\mathrm{H}$ stretching vibration of aldehyde group, which may be generated during grafting of PMMA to cellulose moiety of bamboo specimen.

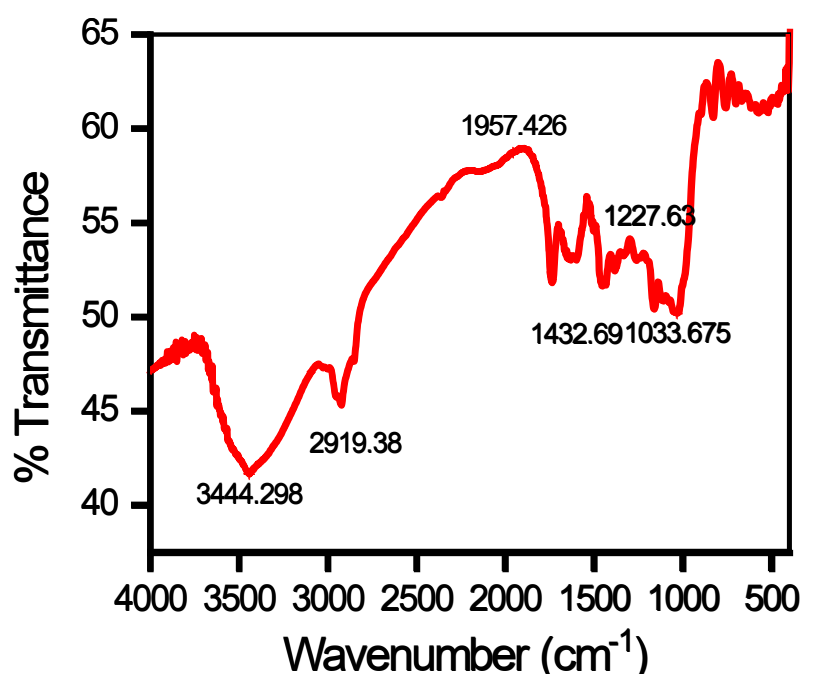

Figure 1. IR spectrum of bamboo. 


\subsection{SEM analysis}

Fracture surface morphology of the bamboo-polymer composite specimens is shown in Figure. 2. Micro structural studies of the virgin bamboo (Figure. 2a) revealed many voids in the inner part of the bamboo. The fracture of fibre shows that each fiber, irrespective of its position, contained many fibrils. The cross section of fibrils appeared as hexagonal honeycombs bonded with each other. Again, fibril contains much continuously elongated cellulose in twisted forms. Overall bamboo fibre contains many fibrils, composed of cellulose. Figure $2 \mathrm{~b}$ represents microstructure of alkali leached bamboo specimen where porosity was more than the virgin specimen due to the removal of some soluble sugars and hemicellulose. Figure 2c-2e represent the SEM micrographs of bamboo-poly (methyl methacrylate), bamboo-poly (methylacrylate) and bamboo-phenolic resin composites respectively. From the micrographs it was clear that polymers were evenly impregnated making a good bond with bamboo. Polymer impregnation into the bamboo matrix was also evinced from the higher density of the bamboo-polymer composites than that of the virgin bamboo.
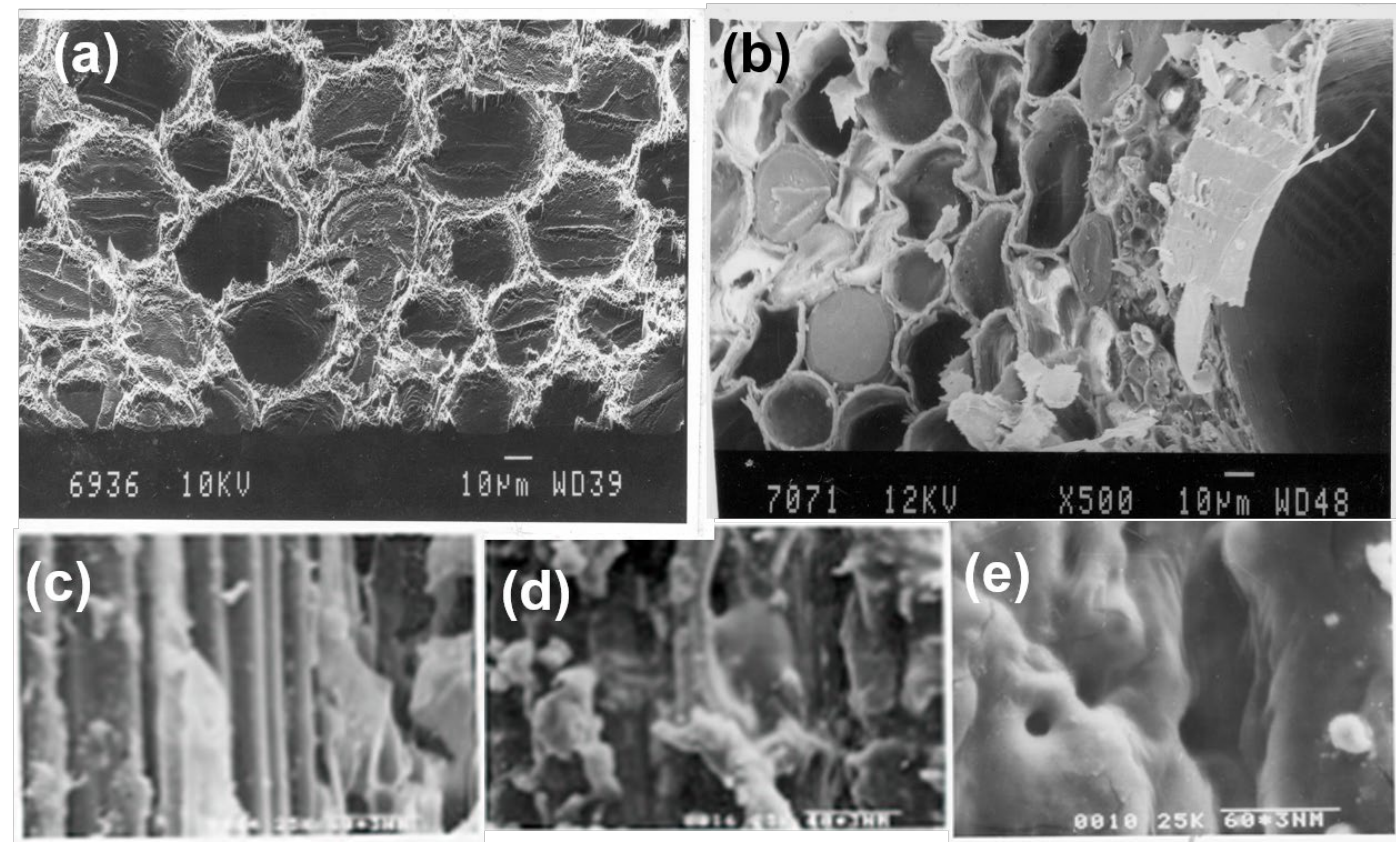
Figure. 2 SEM micrograph of (a) raw bamboo (b) alkali treated bamboo (c) Bamboo-PMMA (d) Bamboo-PMA (e) Bamboo-PF

\subsection{Tensile strength analysis}

One of the most important characteristics of these composites is their mechanical property. The values of tensile strength, elongation and modulus are given in Table 3.

Table 3. Mechanical properties of bamboo-polymer composites.

\begin{tabular}{llllll}
\hline Sample Designation & $\begin{array}{l}\text { Strain } \\
(\mathrm{mm} / \mathrm{mm})\end{array}$ & $\begin{array}{l}\text { Modulus } \\
(\mathrm{GPa})\end{array}$ & $\begin{array}{l}\text { Tensile } \\
\text { Strength } \\
(\mathrm{MPa})\end{array}$ & $\begin{array}{l}\text { Toughness } \\
(\text { Joule) }\end{array}$ & $\begin{array}{l}\text { Elongation } \\
\text { at Break } \\
(\%)\end{array}$ \\
\hline B-PMMA (bul) & 0.059 & 13.468 & 356.83 & 5.07 & 5.93 \\
B-PMA (bul) & 0.034 & 11.713 & 272.43 & 2.15 & 3.43 \\
B-PS (bul) & 0.034 & 13.468 & 255.32 & 2.53 & 3.37 \\
B-PMMA (sol) & 0.030 & 8.228 & 224.49 & -- & 3.00 \\
B-PMA (sol) & 0.018 & 13.179 & 197.54 & 0.48 & 1.84 \\
B-PS (sol) & 0.066 & 9.045 & 279.20 & 11.40 & 6.60 \\
B -PF & 0.038 & 9.335 & 289.63 & 1.396 & 3.83 \\
Virgin bamboo & 0.028 & 8.492 & 180.42 & -- & 2.83 \\
Alkali treated bamboo & 0.020 & 5.717 & 102.17 & 0.68 & 1.97 \\
\hline
\end{tabular}

The specimen under tensile test was loaded until fracture. Tensile load increased linearly with increasing strain until the point of ultimate load. Partial damage occurred in some specimens when the tensile load reached about $90 \%$ of the ultimate stress. The ultimate load carried by the set of fibers and ultimate extensions before failure were measured. To measure the elongation, two marks were made on the load axis and the change in the distance between the two marks were recorded for different loading conditions. Tensile strength was calculated from the ultimate load and cross-sectional area of fibers. Typical stress-strain curve of virgin bamboo is given in Figure 3. It showed a uniform increase in stress with strain followed by immediate fracture at the maximum load. Below 60 to $65 \%$ of breaking load, a linear relationship was recorded in the load displacement curve. Shin et al. reported the slippage prior breaking in this range for bambooepoxy composites ${ }^{44}$. Similar trends were also observed in all the composites prepared using the 
above-mentioned method. Using the stress strain curve, the tensile strength of alkali-leached bamboo specimen was calculated to be $102 \mathrm{MPa}$. The lower tensile strength of alkali treated bamboo specimen as compared to raw bamboo could be a reflection of poor bonding between fiber and matrix which promoted fracture. This may be due to the partial removal of matrix of bamboo during alkali treatment. Generally, fibers reinforce the matrix when the fiber and matrix are sufficient to restrain the stress distribution. Strength of a composite can achieve optimum levels when it has perfect interfacial adhesion and interfacial strength. From Table 3 it was observed that the tensile strength of B-PMMA and B-PS composites (prepared by bulk polymerization) was $356.83 \mathrm{MPa}$ and $255.32 \mathrm{MPa}$ respectively. Improved tensile properties of all the above-mentioned composites were due to stronger bonding between matrices or more incorporation of polymer into bamboo matrix. The overall stress-strain behavior of all bamboo polymer composites was non-linear. On the other hand, tensile strength of bamboo polymer composite of B-PMMA, B-PS, (prepared by solution polymerization condition) (given in Table 3) was $224.49 \mathrm{MPa}$, and 279.20 MPa respectively. Low tensile strength of the composite may be due to insufficient interfacial bonding or inadequate incorporation of polymer and interfacial bonding or inadequate incorporation of polymer between fiber and matrix plays a vital role in governing the mechanical properties of bamboo. During solution polymerization concentration of polymer was low, which might be a reason for low incorporation of polymer. This may be due to the fact that at low polymer loading the fiber matrix interface becomes weak. The decrease in tensile strength at low polymer loading could be a reflection of poor fiber adhesion between fiber and matrix, which promoted micro crack formation at the interface. Generally, a fiber starts reinforcing the matrix when fibers are sufficient to restrain the matrix leading to uniform stress distribution. The stress-strain curve of bamboo polymer composite predicts general linear elastic behavior of bamboo polymer composite. Tensile load increased linearly with increasing strain until the point of ultimate load, when bamboo fiber underwent breakage exhibiting brittle fracture.

It was observed that bamboo polymer composites had higher strength than that of raw bamboo. The load extension curve obtained during measurement of tensile properties of the BPMMA composite specimen is shown in Figure 3. The general trend of the graph shows a linear increase prior to breaking load. Elongation of bamboo-polymer composites occurs in the range 1.84 to $6.03 \%$. The stress strain curves thus obtained show a uniform increase in strain with 
increasing stress followed by immediate fracture at a maximum load. From the graph it is observed that the behavior of these composite is close to linear elastic and breaking load caused brittle fracture to occur. The modulus of elasticity was relatively low for bamboo and alkali treated bamboo polymer composite and produced large deformation. Swelling and shrinkage occurred due to absorption or release of water respectively. The shrinkage was high for immature bamboo and decreased with maturity. Due to the presence of hydroxyl and other polar groups in various constituents of bamboo matrix moisture regain was high. Ultimate tensile strength of BPF composites was $289.63 \mathrm{MPa}$. The mechanical properties of the grafted or polymer loaded fiber were obtained from tensile tests as a function of the amount of grafted or loaded polymer. This indicates greater bonding between bamboo-matrix and polymer because of the presence of greater number of reactive groups.

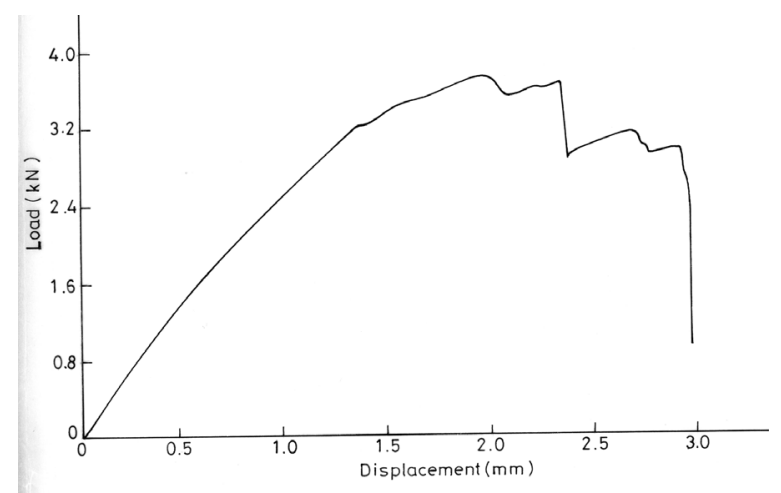

Figure.3 Load extension curve of PMMA-B Composite

The results showed substantial incorporation of polymer in the fiber matrix, which significantly improved the mechanical properties.

\subsection{Water absorption behaviour}

The degree of deterioration and reversibility of properties of the composite materials are largely dependent on the extent of moisture sorption. Natural fiber readily absorbs moisture because they contain abundant polar hydroxide groups, which results in a high moisture absorption level of 
natural fiber reinforced polymer matrix composite and is a major obstacle for extensive application of natural fiber.

The sorption behavior of bamboo and bamboo polymer composites at $25{ }^{0} \mathrm{C}$ are given in Figure 4. It was clear from the graph that bamboo-polymer composites attributed lower moisture uptake than virgin bamboo. Water diffuses through the composite sample mainly by two possible mechanisms.

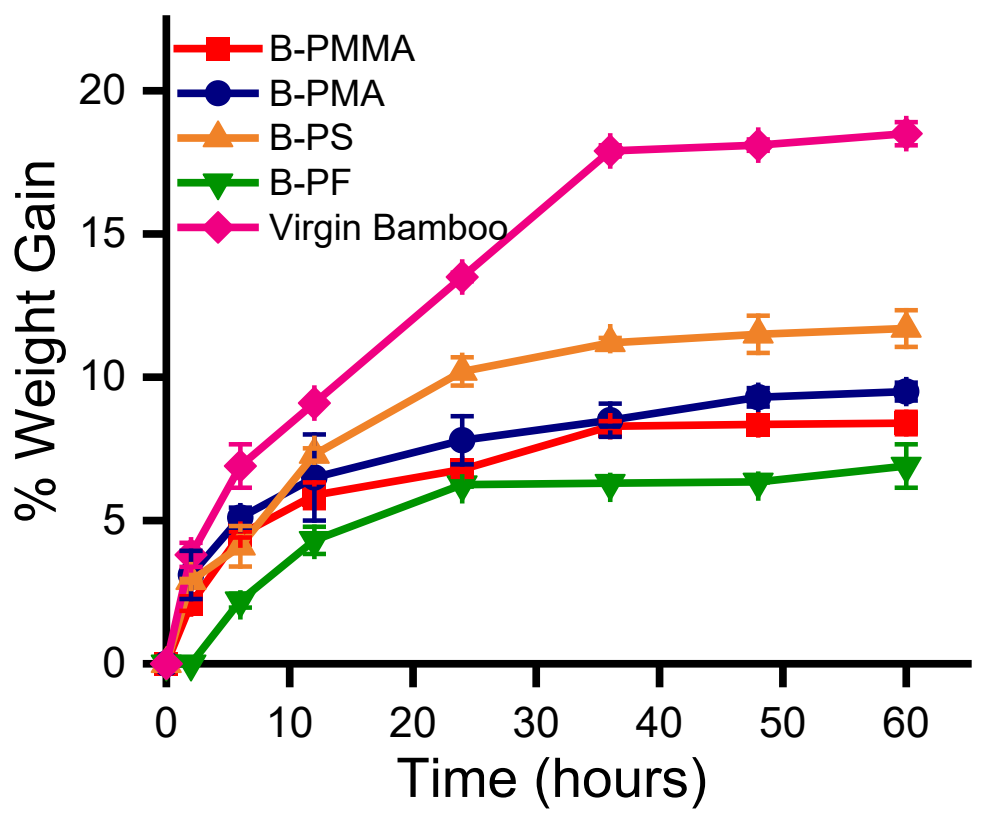

Figure 4. Water absorption characteristics of bamboo and bamboo-polymer composites

Water molecules diffuse directly into the matrix and reach the fibers or they enter into composite by capillary action along the fiber matrix interface followed by diffusion from the interface into bulk resin. The rate of water diffusion depends on the external conditions such as temperature, applied stress as well as internal material states such as debonding at fiber matrix interface, matrix cracking and inherent sorption property of constituent materials. The reduction in moisture level in the composite was attributed to an improved fiber/matrix interfacial bonding that reduces water accumulation in the interfacial voids and prevents water from entering the bamboo fiber. Due to the presence of hydroxyl and other polar groups in the various constituents of bamboo fibers the moisture regain was high which leads to poor wetability with resin and weak interfacial bonding between fibers and relatively more hygroscopic matrices. Future 
research will be based on the measurement of mechanical strength and related properties of the bamboo-polymer composites after soaking of water.

\subsection{Thermal analysis}

Thermo gravimetric analysis was performed to evaluate the thermal stability of bamboo polymer composites. Prior to the thermo gravimetric analysis samples were left in air for 20 days.

Table 4. TGA analysis of bamboo and bamboo-polymer composites.

\begin{tabular}{|c|c|c|c|c|c|c|c|c|c|c|c|c|}
\hline \multirow{3}{*}{$\begin{array}{l}\text { Sample } \\
\text { designation }\end{array}$} & \multicolumn{12}{|c|}{ Decomposition temperature $\left({ }^{0} \mathrm{C}\right)$} \\
\hline & \multicolumn{4}{|c|}{ First stage } & \multicolumn{4}{|c|}{ Second stage } & \multicolumn{4}{|c|}{ Third stage } \\
\hline & Initial & Peak & Final & $\begin{array}{l}\% \mathrm{Wt} \\
\text { Loss }\end{array}$ & Initial & Peak & Final & $\begin{array}{l}\% \mathrm{Wt} \\
\text { Loss }\end{array}$ & Initial & Peak & Final & $\begin{array}{l}\% \mathrm{Wt} \\
\text { Loss }\end{array}$ \\
\hline $\mathrm{B}$ & 22 & 80 & 90 & 17 & 90 & 265 & 387 & 54 & 387 & 395 & 997 & 20 \\
\hline PMMA & 24 & 132 & 132 & 9 & 132 & 270 & 409 & 80 & 409 & 513 & 997 & 11 \\
\hline PMMA-B & 19 & 100 & 112 & 5 & 112 & 395 & 482 & 60 & 482 & 510 & 1010 & 15 \\
\hline PF-B & 22 & 125 & 197 & 12 & 197 & 420 & 532 & 37 & 532 & 560 & 987 & 25 \\
\hline
\end{tabular}

Details of thermal degradation patterns of the virgin bamboo and bamboo-polymer composites are obtained from the TGA curves and included in Table 4. TGA curves of virgin bamboo, PMMA, B-PMMA composites, B- PF composites are given in Figure. 5a-.5d. TGA curve of virgin bamboo has shown three distinct stages of degradation. Initial stage corresponds to a small loss in weight due to evaporation of absorbed moisture and it occurred nearly at $22-90^{\circ} \mathrm{C}$. The second stage was associated with a sharp loss in weight (54\%). Third stage of decomposition starts at $387^{\circ} \mathrm{C}$. In both B-PMMA and B-PF composites, the first stage of decomposition occurred nearly at $19-112^{\circ} \mathrm{C}$ and $22-197^{\circ} \mathrm{C}$ respectively. In case of B- PMMA composite maximum weight loss occurred during the second stage degradation (60\%). But in case of B-PF composite, comparable mass occurred in the second and third stages of decomposition. It was also observed that middle zone decomposition temperatures of both B-PMMA, B-PF composites were higher $\left(340^{\circ} \mathrm{C}, 420^{\circ} \mathrm{C}\right)$ than those of bamboo $\left(265^{\circ} \mathrm{C}\right)$, PMMA $\left(270^{\circ} \mathrm{C}\right)$. Total weight losses are much less in case of the composite. From TGA analysis it may be concluded that the thermal stability of bamboo polymer composites have been improved after polymerization. However 
experimental results at present level don't warrant a detailed explanation. More explanation on the thermal stability of the bamboo polymer composites needs further investigation.

(a)

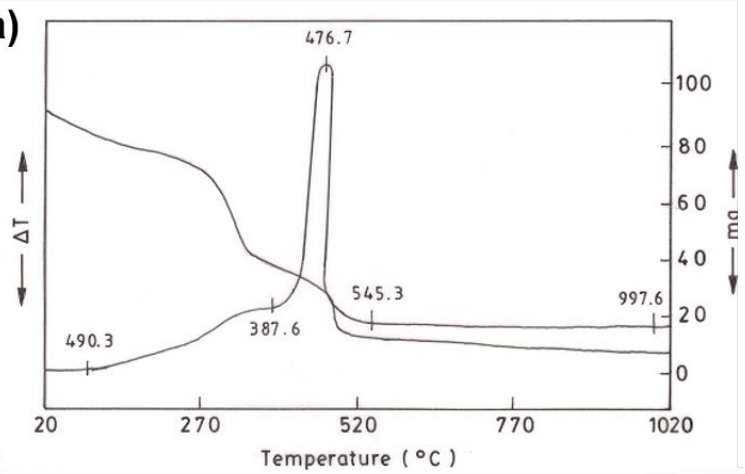

(c)

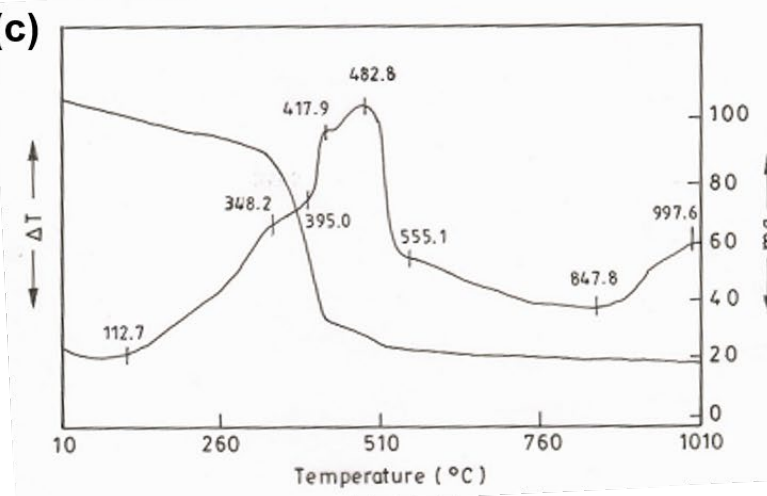

(b)

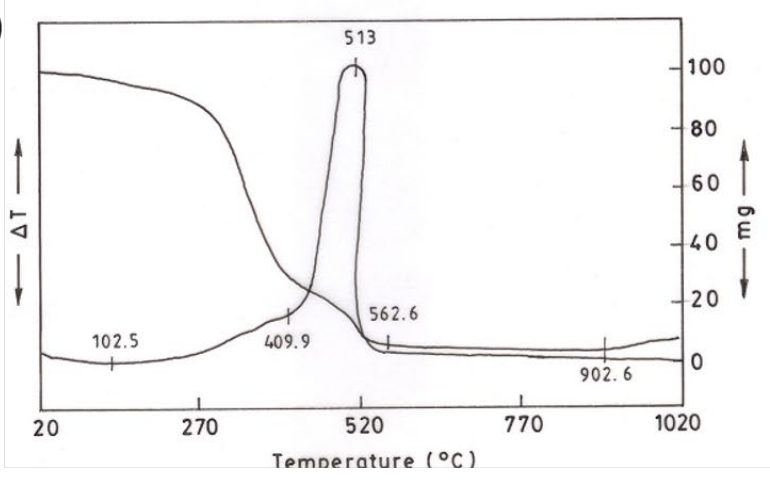

(d)

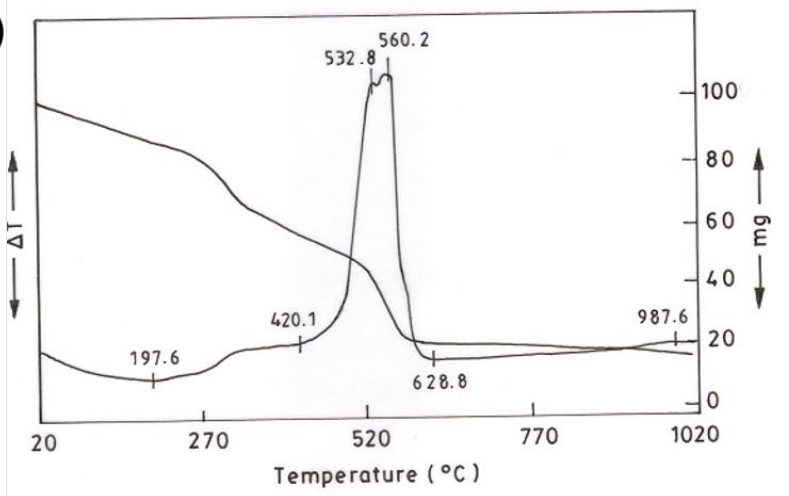

Figure. 5 Thermal gravimetric curves of (a) virgin bamboo (b) PMMA (c) PMMA-B composite (d) PF-B composite.

3.5 Durability study in boiling tetrahydrofuran (THF) and dimethyl formamide (DMF)

Durability of the above-mentioned polymer composites (after curing) was measured by measuring the weight loss after refluxing in THF and DMF for $24 \mathrm{~h}$ and $72 \mathrm{~h}$. The data are presented in Table 5. The results showed that bamboo polymer composites exhibited slightly higher weight loss in DMF compared to that in THF. The higher weight loss in DMF was due to the prolonged heating at $150{ }^{0} \mathrm{C}$. B-PF composites showed almost negligible weight loss in both the solvents and this may be due to higher degree of cross-linking. 
Table 5 Weight loss post in boiling tetrahydrofuran and dimethyl formamide

\begin{tabular}{|l|l|l|l|}
\hline Leachant & $\begin{array}{l}\text { Sample } \\
\text { designation }\end{array}$ & $\begin{array}{l}\text { \% weight } \\
\text { refluxing }\end{array}$ & loss after \\
\cline { 3 - 4 } & & $24 \mathrm{~h}$ & $72 \mathrm{~h}$ \\
\hline THF & B-PMMA & 1.32 & 1.71 \\
& B-PMA & 1.71 & 1.92 \\
& B-ST & 1.26 & 1.73 \\
& B-PF & 0.00 & 0.00 \\
& B-PAN & 2.14 & 3.40 \\
& Virgin & 2.16 & 3.29 \\
DMF & B-PMMA & 1.17 & 1.32 \\
& B-PMA & 1.72 & 2.51 \\
& B-ST & 1.56 & 2.18 \\
& B-PF & 1.12 & 2.01 \\
& B-PAN & 1.96 & 2.31 \\
& Virgin & 3.78 & 4.2 \\
\hline
\end{tabular}

\section{Conclusion}

The above results have been demonstrated that a useful biocompatible composite material can be manufactured from bamboo fibre composite, and this can be regarded as a successful engineering material particularly lightweight building material with biocompatible and green properties.

\section{Acknowledgement}

The financial assistance received from Aeronautics Research and Development Board (ARDB), Govt. of India in carrying this investigation is gratefully acknowledged. 


\section{References}

1. Ahmad, M.; Kamke, F. A., Analysis of Calcutta bamboo for structural composite materials: physical and mechanical properties. Wood Science and Technology 2005, 39 (6), 448459.

2. Ray, P.; Gidley, D.; Badding, J. V.; Lueking, A. D., UV and chemical modifications of polymer of Intrinsic Microporosity 1 to develop vibrational spectroscopic probes of surface chemistry and porosity. Microporous and Mesoporous Materials 2019, 277, 29-35.

3. Lager, J. R.; June, R. R., Compressive Strength of Boron-Epoxy Composites. Journal of Composite Materials 1969, 3 (1), 48-56.

4. Ray, P.; Xu, E.; Crespi, V. H.; Badding, J. V.; Lueking, A. D., In situ vibrational spectroscopy of adsorbed nitrogen in porous carbon materials. Physical Chemistry Chemical Physics 2018, 20 (22), 15411-15418.

5. Singh, T.; Rathi, M. K.; Patnaik, A.; Chauhan, R.; Ali, S.; Fekete, G., Application of waste tire rubber particles in non-asbestos organic brake friction composite materials. Materials Research Express 2018, 6 (3), 035703.

6. Kulkarni, A. G.; Satyanarayana, K. G.; Rohatgi, P. K.; Vijayan, K., Mechanical properties of banana fibres (Musa sepientum). Journal of Materials Science 1983, 18 (8), 22902296.

7. White, N. M.; Ansell, M. P., Straw-reinforced polyester composites. Journal of Materials Science 1983, 18 (5), 1549-1556.

8. Sarker, N. C.; Ray, P.; Pfau, C.; Kalavacharla, V.; Hossain, K.; Quadir, M., Development of Functional Nanomaterials from Wheat Bran Derived Arabinoxylan for Nucleic Acid Delivery. Journal of Agricultural and Food Chemistry 2020, 68 (15), 4367-4373.

9. Indra Reddy, M.; Anil Kumar, M.; Anki Reddy, S.; Vijaya Kumar Raju, P., Thermo physical properties of Jute, Pineapple leaf and Glass fiber reinforced polyester hybrid composites. Materials Today: Proceedings 2018, 5 (10, Part 1), 21055-21060.

10. Sharma, B.; Gatóo, A.; Bock, M.; Ramage, M., Engineered bamboo for structural applications. Construction and Building Materials 2015, 81, 66-73.

11. Liese, W., Research on bamboo. Wood Science and Technology 1987, 21 (3), 189-209.

12. Osorio, L.; Trujillo, E.; Van Vuure, A. W.; Verpoest, I., Morphological aspects and mechanical properties of single bamboo fibers and flexural characterization of bamboo/epoxy composites. Journal of reinforced plastics and composites 2011, 30 (5), 396-408.

13. Okubo, K.; Fujii, T.; Yamamoto, Y., Development of bamboo-based polymer composites and their mechanical properties. Composites Part A: Applied Science and Manufacturing 2004, 35 (3), 377-383.

14. Kunst, F.; Ogasawara, N.; Moszer, I.; Albertini, A. M.; Alloni, G.; Azevedo, V.; Bertero, M. G.; Bessières, P.; Bolotin, A.; Borchert, S.; Borriss, R.; Boursier, L.; Brans, A.; Braun, M.; Brignell, S. C.; Bron, S.; Brouillet, S.; Bruschi, C. V.; Caldwell, B.; Capuano, V.; Carter, N. M.; Choi, S. K.; Codani, J. J.; Connerton, I. F.; Cummings, N. J.; Daniel, R. A.; Denizot, F.; Devine, K. M.; Düsterhöft, A.; Ehrlich, S. D.; Emmerson, P. T.; Entian, K. D.; Errington, J.; Fabret, C.; Ferrari, E.; Foulger, D.; Fritz, C.; Fujita, M.; Fujita, Y.; Fuma, S.; Galizzi, A.; Galleron, N.; Ghim, S. Y.; Glaser, P.; Goffeau, A.; Golightly, E. J.; Grandi, G.; 
Guiseppi, G.; Guy, B. J.; Haga, K.; Haiech, J.; Harwood, C. R.; Hénaut, A.; Hilbert, H.; Holsappel, S.; Hosono, S.; Hullo, M. F.; Itaya, M.; Jones, L.; Joris, B.; Karamata, D.; Kasahara, Y.; Klaerr-Blanchard, M.; Klein, C.; Kobayashi, Y.; Koetter, P.; Koningstein, G.; Krogh, S.; Kumano, M.; Kurita, K.; Lapidus, A.; Lardinois, S.; Lauber, J.; Lazarevic, V.; Lee, S. M.; Levine, A.; Liu, H.; Masuda, S.; Mauël, C.; Médigue, C.; Medina, N.; Mellado, R. P.; Mizuno, M.; Moestl, D.; Nakai, S.; Noback, M.; Noone, D.; O'Reilly, M.; Ogawa, K.; Ogiwara, A.; Oudega, B.; Park, S. H.; Parro, V.; Pohl, T. M.; Portetelle, D.; Porwollik, S.; Prescott, A. M.; Presecan, E.; Pujic, P.; Purnelle, B.; Rapoport, G.; Rey, M.; Reynolds, S.; Rieger, M.; Rivolta, C.; Rocha, E.; Roche, B.; Rose, M.; Sadaie, Y.; Sato, T.; Scanlan, E.; Schleich, S.; Schroeter, R.; Scoffone, F.; Sekiguchi, J.; Sekowska, A.; Seror, S. J.; Serror, P.; Shin, B. S.; Soldo, B.; Sorokin, A.; Tacconi, E.; Takagi, T.; Takahashi, H.; Takemaru, K.; Takeuchi, M.; Tamakoshi, A.; Tanaka, T.; Terpstra, P.; Tognoni, A.; Tosato, V.; Uchiyama, S.; Vandenbol, M.; Vannier, F.; Vassarotti, A.; Viari, A.; Wambutt, R.; Wedler, E.; Wedler, H.; Weitzenegger, T.; Winters, P.; Wipat, A.; Yamamoto, H.; Yamane, K.; Yasumoto, K.; Yata, K.; Yoshida, K.; Yoshikawa, H. F.; Zumstein, E.; Yoshikawa, H.; Danchin, A., The complete genome sequence of the Gram-positive bacterium Bacillus subtilis. Nature 1997, 390 (6657), 249-256.

15. Ray, P.; Ferraro, M.; Haag, R.; Quadir, M., Dendritic Polyglycerol-Derived NanoArchitectures as Delivery Platforms of Gemcitabine for Pancreatic Cancer. Macromol Biosci 2019, 19 (7), e1900073.

16. Plank, J., Applications of biopolymers and other biotechnological products in building materials. Applied microbiology and biotechnology 2004, 66 (1), 1-9.

17. Ray, P.; Kale, N.; Quadir, M., New Side Chain Design for pH-Responsive Block Copolymers for Drug Delivery. Colloids and Surfaces B: Biointerfaces 2021, 111563.

18. Abdullah, C. S.; Ray, P.; Alam, S.; Kale, N.; Aishwarya, R.; Morshed, M.; Dutta, D.; Hudziak, C.; Banerjee, S. K.; Mallik, S.; Banerjee, S.; Bhuiyan, M. S.; Quadir, M., Chemical Architecture of Block Copolymers Differentially Abrogate Cardiotoxicity and Maintain the Anticancer Efficacy of Doxorubicin. Molecular Pharmaceutics 2020.

19. Ray, P.; Dutta, D.; Haque, I.; Nair, G.; Mohammed, J.; Parmer, M.; Kale, N.; Orr, M.; Jain, P.; Banerjee, S.; Reindl, K. M.; Mallik, S.; Kambhampati, S.; Banerjee, S. K.; Quadir, M., pH-Sensitive Nanodrug Carriers for Codelivery of ERK Inhibitor and Gemcitabine Enhance the Inhibition of Tumor Growth in Pancreatic Cancer. Molecular Pharmaceutics 2020.

20. Trubetskoy, V. S., Polymeric micelles as carriers of diagnostic agents. Advanced drug delivery reviews 1999, 37 (1-3), 81-88.

21. Ray, P.; Confeld, M.; Borowicz, P.; Wang, T.; Mallik, S.; Quadir, M., PEG-b-poly (carbonate)-derived nanocarrier platform with $\mathrm{pH}$-responsive properties for pancreatic cancer combination therapy. Colloids and Surfaces B: Biointerfaces 2019, 174, 126-135.

22. Fleige, E.; Quadir, M. A.; Haag, R., Stimuli-responsive polymeric nanocarriers for the controlled transport of active compounds: concepts and applications. Adv Drug Deliv Rev 2012, 64 (9), 866-84.

23. Krause, W., Delivery of diagnostic agents in computed tomography. Advanced drug delivery reviews 1999, 37 (1-3), 159-173.

24. Ray, P.; Nair, G.; Ghosh, A.; Banerjee, S.; Golovko, M. Y.; Banerjee, S. K.; Reindl, K. M.; Mallik, S.; Quadir, M., Microenvironment-sensing, nanocarrier-mediated delivery of combination chemotherapy for pancreatic cancer. Journal of Cell Communication and Signaling 2019. 
25. Haag, R.; Kratz, F., Polymer Therapeutics: Concepts and Applications. Angewandte Chemie International Edition 2006, 45 (8), 1198-1215.

26. Ray, P.; Alhalhooly, L.; Ghosh, A.; Choi, Y.; Banerjee, S.; Mallik, S.; Banerjee, S.; Quadir, M., Size-Transformable, Multifunctional Nanoparticles from Hyperbranched Polymers for Environment-Specific Therapeutic Delivery. ACS Biomaterials Science \& Engineering 2019, 5 (3), 1354-1365.

27. Clément, M.; Abdellah, I.; Ray, P.; Martini, C.; Coppel, Y.; Remita, H.; Lampre, I.; Huc, V., Synthesis and NMR study of trimethylphosphine gold(i)-appended calix[8]arenes as precursors of gold nanoparticles. Inorganic Chemistry Frontiers 2020.

28. Ray, P.; Clément, M.; Martini, C.; Abdellah, I.; Beaunier, P.; Rodriguez-Lopez, J.-L.;

Huc, V.; Remita, H.; Lampre, I., Stabilisation of small mono- and bimetallic gold-silver nanoparticles using calix[8]arene derivatives. New Journal of Chemistry 2018, 42 (17), 1412814137.

29. André, E.; Boutonnet, B.; Charles, P.; Martini, C.; Aguiar-Hualde, J.-M.; Latil, S.; Guérineau, V.; Hammad, K.; Ray, P.; Guillot, R.; Huc, V., A New, Simple and Versatile Strategy for the Synthesis of Short Segments of Zigzag-Type Carbon Nanotubes. Chemistry - A European Journal 2016, 22 (9), 3105-3114.

30. Ray, P.; Gray, J. L.; Badding, J. V.; Lueking, A. D., High-Pressure Reactivity of Triptycene Probed by Raman Spectroscopy. The Journal of Physical Chemistry B 2016, 120 (42), 11035-11042.

31. Chaudhuri, S.; Maity, S.; Roy, M.; Ray, P.; Ray, J. K., A Vinyl Radical Cyclization Route to Hydroxycyclohexene Fused Carbocycles. Asian Journal of Chemistry 2016, 28 (1).

32. Ray, J. K.; Paul, S.; Ray, P.; Singha, R.; Rao, D. Y.; Nandi, S.; Anoop, A., Pdcatalyzed intramolecular sequential Heck cyclization and oxidation reactions: a facile pathway for the synthesis of substituted cycloheptenone evaluated using computational studies. New Journal of Chemistry 2017, 41 (1), 278-284.

33. Ray, J. K.; Singha, R.; Ray, D.; Ray, P.; Rao, D. Y.; Anoop, A., Palladium-catalyzed expedient Heck annulations in 1-bromo-1,5-dien-3-ols: Exceptional formation of fused bicycles. Tetrahedron Letters 2019, 60 (13), 931-935.

34. Ray, P., Interactions of nitrogen and hydrogen with various 1D and 3D carbon materials probed via in-situ vibrational spectroscopy. Ph. D. Thesis 2016.

35. Wang, C.-Y.; Ray, P.; Gong, Q.; Zhao, Y.; Li, J.; Lueking, A. D., Influence of gas packing and orientation on FTIR activity for $\mathrm{CO}$ chemisorption to the $\mathrm{Cu}$ paddlewheel. Physical Chemistry Chemical Physics 2015, 17 (40), 26766-26776.

36. Ray, P., Interactions of nitrogen and hydrogen with various 1D and 3D carbon materials probed via in-situ vibrational spectroscopy. 2016.

37. Confeld, M. I.; Mamnoon, B.; Feng, L.; Jensen-Smith, H.; Ray, P.; Froberg, J.; Kim, J.; Hollingsworth, M. A.; Quadir, M.; Choi, Y.; Mallik, S., Targeting the tumor core: hypoxiaresponsive nanoparticles for delivery of chemotherapy to pancreatic tumors. Molecular Pharmaceutics 2020.

38. Ghosh, A.; Sarkar, S.; Ghosh, S.; Ray, P.; Quadir, M.; Banerjee, S. K.; Banerjee, S., Abstract 1234: Zoledronic acid-induced suppression of invasive phenotypes of pancreatic cancer cells is mediated through downregulation of CYR61/CCN1. Cancer Research 2019, 79 (13 Supplement), 1234.

39. Das, A.; Haque, I.; Ray, P.; Ghosh, A.; Dutta, D.; Quadir, M.; De, A.; Gunewardena, S.; Chatterjee, I.; Banerjee, S.; Weir, S.; Banerjee, S. K., CCN5 activation by free or 
encapsulated EGCG is required to render triple-negative breast cancer cell viability and tumor progression. Pharmacol Res Perspect 2021, 9 (2), e00753.

40. Ray, P.; Haideri, N.; Haque, I.; Mohammed, O.; Chakraborty, S.; Banerjee, S.; Quadir, M.; Brinker, A. E.; Banerjee, S. K., The Impact of Nanoparticles on the Immune System: A Gray Zone of Nanomedicine. Journal of Immunological Sciences 2021, 5 (1).

41. Amada, S.; Ichikawa, Y.; Munekata, T.; Nagase, Y.; Shimizu, H., Fiber texture and mechanical graded structure of bamboo. Composites Part B: Engineering 1997, 28 (1), 13-20.

42. Jain, S.; Jindal, U. C.; Kumar, R., Development and fracture mechanism of the bamboo/polyester resin composite. Journal of Materials Science Letters 1993, 12 (8), 558-560.

43. Jain, S.; Kumar, R.; Jindal, U. C., Mechanical behaviour of bamboo and bamboo composite. Journal of Materials Science 1992, 27 (17), 4598-4604.

44. Shin, F. G.; Xian, X. J.; Zheng, W. P.; Yipp, M. W., Analyses of the mechanical properties and microstructure of bamboo-epoxy composites. Journal of Materials Science 1989, 24 (10), 3483-3490.

45. Deshpande, A. P.; Bhaskar Rao, M.; Lakshmana Rao, C., Extraction of bamboo fibers and their use as reinforcement in polymeric composites. Journal of Applied Polymer Science 2000, $76(1), 83-92$. 